\title{
UN INTENTO DE SOLUCIÓN A LA PARADOJA DEL MENTIROSO: ALGUNOS APORTES DESDE LA FENOMENOLOGÍA
}

Omar Valencia G.

Pontificia Universidad Católica del Perú

La paradoja del mentiroso lleva siglos atormentando la mente de filósofos y lógicos. El presente texto intenta una solución siguiendo la siguiente tesis: la paradoja no puede ser resuelta por la lógica dado que lo implicado en ella trasciende las fronteras de esa disciplina. Lo que trasciende estas fronteras (establecidas en gran medida por Frege, en tanto padre de la lógica moderna) es el propio ser humano como ser capaz de articular sentido. De ahí la necesidad de explorar cómo la fenomenología aborda al ser humano para reconcebir también al lenguaje y al tiempo. Este giro será crucial para entender por qué el problema de dicha paradoja es la autorreferencialidad, lo que también conlleva a reinterpretar qué se entiende por niveles de lenguaje (sea en la forma de Tarski o de Kripke).

Palabras clave:

paradoja del mentiroso, lógica, lenguaje, fenomenología, sujeto 
Cada disciplina, al acotar su campo de estudio, está obligada también a delimitar qué problemas le corresponde afrontar y cuáles tendrán que ser delegados a otras ramas del saber. Esto obviamente no significa que se creen compartimentos estancos entre ellos: una disciplina puede recurrir a otra para tomar prestados ciertos paradigmas (como en el paso del estructuralismo de la lingüística a las ciencias sociales) o puede haber problemas que sean compartidos por varias (como en el caso del problema de la relación mente-cerebro compartido por la psicología, la neurociencia, la inteligencia artificial, la filosofía e incluso la genética). El punto es que una vez fijado qué tipo de objetividad abordará, tendrá entonces también señalado qué tipos de objetividades no abordará.

En el caso de la lógica moderna y de la semántica que la acompaña, la delimitación de su área de estudio se consolida entre finales del siglo XIX y principios del $X X$, y suele reconocerse a Frege como el gran iniciador, seguido inmediatamente por Russell y Whitehead con su Principia mathematica. Las tesis de estos pensadores pueden haber sido duramente criticadas por lógicos, filósofos analíticos y matemáticos; empero, lo que nos interesa ahora no son tanto las tesis propuestas por ellos, sino el campo de estudio que ellos asumen y que es presupuesto, como telón de fondo, para la formulación de tales tesis. De esta forma, veremos cómo la paradoja del mentiroso depende de una determinada manera de entender al ser humano y al lenguaje que Frege delineó. Principalmente tendrá que entenderse cómo él deja el ámbito subjetivo fuera del campo de estudio de la lógica, pero lo hace porque maneja un concepto bastante moderno de sujeto. ¿Qué sucede entonces si nos proponemos cuestionar aquella noción de sujeto? Reinterpretándola, podremos darnos cuenta de que la autorreferencialidad (un rasgo esencial de la paradoja) no existe realmente, pues una proposición nunca remite a sí misma; en el fondo, es siempre un sujeto el que remite a un objeto (sea este un objeto en sentido usual o un objeto lingüístico).

En lo que sigue, entonces, se procederá del siguiente modo: en primer lugar, se hará una presentación panorámica de la paradoja del mentiroso, pasando revista, rápidamente, a los modos en que ha tratado de ser superada por parte de Tarski y Kripke, y se señalarán las acotaciones y críticas que ya otros comentaristas han hecho. En segundo lugar, rastrearemos la raíz histórica del 
problema en aquel que le dio el impulso inicial a la lógica moderna: Frege. Se indicará, de esta manera, cómo los lógicos han tendido a asumir un rasgo característico suyo: el descarte (o, en el mejor de los casos, una interpretación parcial) de lo subjetivo. En tercer lugar, buscaremos en la fenomenología un modo de reinterpretar al ser humano para que ya no sea entendido bajo el paradigma del sujeto, y al lenguaje para que no sea entendido solo como un conjunto articulado de enunciados. Finalmente, en una cuarta sección, se señalará qué conclusiones podemos sacar con respecto al metalenguaje y la autorreferencialidad de la paradoja.

\section{§ 1. Presentación panorámica de la paradoja ${ }^{1}$}

La versión histórica más vieja de la paradoja es asignada a Epiménides de Creta, quien habría dicho alguna vez que todos los cretenses eran mentirosos. Por mor de simplicidad, recurriremos a la forma más sencilla de esta paradoja: "Esta oración es falsa"2. Como se sabe, si se dice que esta oración es verdadera, en tanto que predica que lo dicho por ella es algo falso, sería también falsa; y si se dice que es falsa, en tanto que predica que lo dicho por ella es algo falso, entonces se haría verdadera ${ }^{3}$.

\footnotetext{
' En esta primera sección nos limitaremos a presentar, muy sucintamente, los retos que debe asumir, según los propios lógicos, cualquier intento por solucionar la paradoja. En gran medida, es lo que se encuentra en la mayoría de libros actuales que refieran al tema.

${ }^{2}$ En realidad, no es únicamente por la simplicidad. Se podría también usar una formulación como "estoy mintiendo", pero esta oración complica el caso, porque en "mentir" hay que tener en cuenta la intención del hablante y la información disponible que tiene al momento de la enunciación; de ahí que, por ejemplo, alguien pueda mentir (muy ligado a la voluntad de engañar) y a la vez decir algo verdadero. Por ejemplo: si A le pregunta a B dónde está el cine y B le dice "hacia el norte" cuando en verdad cree que está hacia el sur, entonces está mintiendo; sin embargo, si resulta que el cine realmente sí estaba hacia el norte (y por lo tanto el engaño de B no funcionó), entonces estaba dando una información verdadera. Para evitar este tipo de problemas, analizaremos las formas de la paradoja en la que se hable directamente de verdad y falsedad.

${ }^{3}$ Cabe mencionar aquí también que, en el momento en que se presenta la paradoja a alguien que no la conoce, suele hacerse por escrito: suele escribirse la oración. Esto no es algo neutral, dado que la escritura brinda independencia a lo proferido, le brinda una fijeza en el trazo que lo hace susceptible de un análisis en tanto objeto lingüístico. Hay que tener muy en cuenta esto, pues, como veremos más adelante, el núcleo de la paradoja se encuentra justamente en quedar atrapado en la concepción del lenguaje en tanto objeto lingüístico.
} 
Hagamos una breve revisión de los principales intentos por superar la paradoja en el siglo XX. Todas han sido sumamente ingeniosas, pero han presentado algún punto débil ${ }^{4}$.

La solución propuesta por $\operatorname{Tarski}^{5}$ consiste en hacer una diferencia entre niveles del lenguaje ${ }^{6}$ para evitar la paradoja. Según su propuesta, ninguna oración tiene su valor de verdad en el mismo nivel del lenguaje en la que se manifiesta; si esto es así, concluye Tarski, no hay realmente enunciados autorreferenciales con respecto al valor veritativo, sino que dicha referencia se hace siempre desde un nivel superior. Lo que debemos hacer para hallar dicho valor de verdad es subir un nivel, pasando a un metalenguaje con respecto del cual el primer nivel sería el lenguaje objeto. La pregunta que se hace a continuación es iqué sucede con lo que estoy diciendo en aquel metalenguaje?, pues si lo afirmado en este metalenguaje es la verdad del lenguaje objeto, icómo se determina la verdad en ese metalenguaje? Tendría que ser en un meta-metalenguaje. Tarski propone entonces un esquema de jerarquías de lenguaje:

$L_{3}$ : metalenguaje de $L_{2}$, aquí se predica la verdad ${ }_{c}$ de $L_{2}$ $L_{2}$ : metalenguaje de $L_{1}$, aquí se predica la verdad ${ }_{b}$ de $L_{1}$ $\mathrm{L}_{1}$ : metalenguaje de $\mathrm{L}_{0}$, aquí se predica la verdad de $\mathrm{L}_{0}$ $\mathrm{L}_{0}$ : lenguaje objeto, aquí no hay predicados de verdad

\section{Entes - eventos}

El problema aquí, además de parecer una respuesta algo ad hoc para este problema, es que no tendríamos un criterio específico para detenernos en este ascenso de metalenguaje a metalenguaje; es decir, no se explica bien cómo evitar el seguir remontándose de un nivel a otro ad infinitum. Además,

\footnotetext{
${ }^{4}$ Debido a la extensión de este artículo, solo haremos una presentación bastante escueta de las propuestas. Para tener un panorama más detallado, cf. Kirkham, Richard, Theories of Truth, Cambridge: MIT Press, 1992; Simmons, Keith, Universality and the Liar, Nueva York: Cambridge University Press, 1993, especialmente el capítulo I; Dowden, Bradley, "The Liar Paradox”, en: Internet Encyclopedia of Philosophy, $2010<$ http://www.iep.utm.edu/par-liar/>.

${ }^{5}$ Cf. Tarski, Alfred, La concepción semántica de la verdad y los fundamentos de la semántica (1944), Buenos Aires: Buena Visión, 1972.

${ }^{6}$ Parecida a la de Tarski es la solución de Russell, que habla también de niveles de lenguaje pero con un análisis de tipos o géneros (types). Dado que la estrategia de ambos pasa por la construcción de niveles, que es el núcleo de sus propuestas, hemos decidido no incluir a Russell. Cf. Russell, Bertrand, “La lógica matemática y su fundamentación en la teoría de los tipos”, en: Ensayos sobre lógica y conocimiento, Madrid: Taurus, 1956.
} 
Tarski tendría problemas para lidiar con una versión de la paradoja que evade la autorreferencia':

A: "Lo que dice la proposición B es verdadero".

B: "Lo que dice la proposición A es falso".

Lo que se manifiesta en ella es la mutua referencialidad. Aquí se hace uso de dos miembros que se refieren entre sí. Se ha creado entonces lo que podríamos llamar una "torsión" ${ }^{8}$ de los niveles del lenguaje en el que lo que dice A es un metalenguaje cuyo lenguaje objeto sería lo dicho por B; pero esto es a la vez un metalenguaje cuyo lenguaje objeto sería lo dicho por $A$.

Por su parte, la teoría de Kripke, presentada en "Esbozo de una teoría de la verdad”, es bastante compleja por la formalización a la que recurre; por ello, solo señalaré las diferencias con Tarski para pasar, posteriormente, a los puntos débiles que puede hallarse en ambos a la vez.

Kripke se propone elaborar un modelo en el que también haya niveles de lenguaje, pero de tal modo que el predicado de verdad esté en el mismo nivel que el enunciado del cual se predica y no en uno superior. Para esto, apelará a que tenemos que considerar una lógica que no sea bivalente; es decir, que tenemos que considerar que las proposiciones pueden ser verdaderas, falsas 0 ni verdaderas ni falsas (valor veritativo indeterminado). Aun así, se hace necesario tener niveles de lenguaje, puesto que con cada nuevo nivel el predicado de verdad pierde indeterminación; esto quiere decir que un enunciado que en un nivel inferior puede tener valor veritativo indeterminado, podría, en un nivel superior, ser declarado verdadero o falso. Además, este nivel superior recoge las determinaciones de los niveles inferiores y a la vez los amplía (por

\footnotetext{
${ }^{7}$ La forma más famosa de representarlo ha sido la presentada por Kripke al inicio de su artículo dedicado al tema ("Outline of a Theory of Truth", en: Journal of Philosophy, LXXII, No. 19 (1972), pp. 690-716). Supongamos que Smith solo dice (a) "La mayoría de los enunciados que Jones dice sobre mí es falsa"; mientras que Jones solo dice tres enunciados: (b) "Smith es un derrochador", (c) "Smith es débil en la lucha contra el crimen" y (d) "Todo lo que dice Smith sobre mí es verdadero". Si por evidencia empírica tenemos que (b) es verdadera y (c) es falsa, entonces la paradoja vuelve a aparecer.

${ }^{8}$ O, como Simmons llama, los “bucles" (loops). Cf. Simmons, Keith, op. cit., p. 5.
} 
ejemplo, si algo ya fue declarado verdadero en $L_{2}$, seguirá siéndolo en $L_{3}, L_{4}$, $L_{5}$, etc. $)^{9}$.

Una de las ventajas del método de Kripke es que, a diferencia del de Tarski, no nos lleva a niveles infinitos en el proceso de remontarnos de metalenguaje a meta-metalenguaje, etc. Según la propuesta de Kripke, todo depende de la complejidad de los enunciados que queramos analizar. Mientras más ascendamos en los niveles de lenguaje, más enunciados irán adquiriendo un valor veritativo hasta que, finalmente, todos los enunciados significativos logren adquirir dicha determinación. En otras palabras, se llegará a alcanzar lo que Kripke llama un punto fijo (fixed point) con el cual ya no se hace necesario continuar con el ascenso. En cuanto a la paradoja, esto es central, pues, según su esquema, el enunciado de la paradoja del mentiroso (en su formulación tradicional) no traería realmente problemas, dado que siempre quedaría con un valor indeterminado de verdad; es decir, nunca se le asigna verdad o falsedad, no importa hasta qué nivel del lenguaje se la lleve. Así, al asumir una lógica trivalente y no una bivalente, deja de ser una amenaza.

Sin embargo, hay un reto que esta propuesta no puede superar: la paradoja del mentiroso reforzada (Strengthened Liar). Esta suele formularse de los siguientes modos: "Esta oración no es verdadera" o "Esta oración es falsa o ni verdadera ni falsa" o "Esta oración es falsa o no tiene valor de verdad". En cada caso, lo que queda claro es que la trivalencia defendida por Kripke es asimilada como acápite del enunciado paradójico, puesto que también este último ha cambiado la bivalencia por la trivalencia ${ }^{10}$.

En suma, los retos que debe asumir cualquier propuesta que quiera solucionar la paradoja debe ser capaz de superar los retos de no ser ad hoc, de la mutua referencia y del mentiroso reforzado. Además, en el caso de que se

\footnotetext{
${ }^{9}$ Para un ejemplo detallado de cómo se aborda esto, cf. Trelles, Óscar, "Un vistazo a la teoría de la verdad por Kripke”, en: Actas del segundo simposio de estudiantes de filosofía, Lima: PUCP, 2004, pp. 206-208, quien ofrece una versión simplificada de Kirkham, Richard, op. cit., pp. 284-286. ${ }^{10}$ El mismo Kripke se había dado cuenta de esto, dejando entrever cierta sospecha sobre las soluciones que, como la suya, pasen por generar niveles del lenguaje. Esto se puede ver en el final de su artículo: "El fantasma de la jerarquía de Tarski está aún con nosotros". Algo curioso que debemos mencionar es que la propuesta de niveles de lenguaje de Tarski ( $y$ también la de Russell) sí logran evitar al mentiroso reforzado.
} 
plantee una solución para un lenguaje lógico formal, no podemos quedarnos tranquilos hasta saber que dicha solución es también válida para los lenguajes naturales".

\section{\$ 2. El núcleo del problema de la paradoja y su raíz histórica: Frege y la objetivación del lenguaje en la lógica}

Tratemos de establecer el núcleo del problema yendo paso a paso y revisando lo que es asumido en la formulación de la paradoja. Dentro de los presupuestos de la paradoja hay uno que no suele revisarse y que es crucial para ella: la autorreferencialidad de una proposición. Se suele asumir sin problemas que un enunciado pueda ser autorreferencial; por ejemplo, no hay ningún problema con el enunciado “Este enunciado tiene cinco palabras”, pues es autorreferente y no tiene paradoja alguna. Sin embargo, sí lo hay; hay una desatención a lo que está presupuesto en esa llamada "autorreferencialidad".

Revisemos la forma de expresar la paradoja en su forma simple para entender esto. Se hacía el siguiente análisis: si asumo que "Esta oración es falsa" tiene la veracidad como valor de verdad, entonces es verdad lo que dicha oración enuncia, es decir que es falsa ( $y$ luego se hace lo mismo designándole la falsedad como valor de verdad). Hemos resaltado intencionalmente el "enuncia", pues es en ese punto donde se juega la referencialidad. Se pregunta ahora: iqué implica la autorreferencialidad aquí? Supongo que se respondería que es obvio: significa que un enunciado habla, dice o enuncia algo sobre sí mismo, se describe a sí mismo. Sin embargo, como buscaremos argumentar, ahí justamente está

\footnotetext{
"Cabe notar que hay intentos más recientes de solución de la paradoja. Uno muy comentado es el de Barwisse y Etchemendy (The Liar: An Essay on Truth and Circularity, Nueva York: Oxford University Press, 1987), que presenta el problema constantemente señalado de no poder decir algo del mundo entero. Otras propuestas son las de Vann McGee (Truth, Vagueness and Paradox, Indianapolis: Hackett, 199I), Hans Herberger ("Paradoxes of Grounding in Semantics", en: Journal of Philosophy, LXVII (1970), pp. 145-167), Anil Gupta ("Truth and Paradox", en: Journal of Philosophical Logic, XI (1982), pp. I-60), Keith Simmons (op. cit.). Parece ser, sin embargo, por las referencias que hacen entre sí y otros artículos, que ninguna de estas propuestas ha dado aún un resultado concluyente sobre la paradoja, sino que son problematizaciones en base a los caminos ya abiertos por Tarski o Kripke, entre otros. Lo que importa para los fines de este artículo es que ninguna de esas propuestas sigue la ruta que se pretende abrir aquí, pues todas ellas se mueven en el terreno de la lógica, mientras que aquí se sugiere que el problema podría estar más allá de la forma en que la lógica procede.
} 
el núcleo del problema. Es tan simple como esto: los enunciados no hablan, no dicen, no enuncian; es decir, no refieren. De ahí que podamos expresarlo así: los enunciados no refieren ni a sí mismos ni a otros enunciados. ¿Qué significa esto? Significa que la posibilidad de referirse a algo, realmente, no es una característica de los enunciados sino del ser humano, del "sujeto"; pero del sujeto no en tanto un conjunto de objetividades psíquicas, de imágenes, recuerdos, etc., sino en tanto articuladora de sentido, una instancia tal que no sea objetivable ${ }^{12}$. Este es el hilo que seguiremos para intentar un camino distinto en pro, no de una resolución, sino de una disolución de la paradoja del mentiroso.

En la próxima sección revisaremos de qué manera se puede reinterpretar al sujeto de la forma en que se está pidiendo aquí; pero antes, en lo que queda de esta sección, se propone, más bien, un rastreo de la fuente que determina el concepto de sujeto para la lógica' ${ }^{13}$.

La idea principal puede enunciarse como sigue: es Frege quien, como padre de la lógica moderna, descarta al sujeto como tema de interés de esa disciplina en general $y$, en particular, de la semántica relacionada a ella. No obstante, hay que notar desde el primer momento que él descarta al sujeto debido a la concepción de "sujeto" que se tenía en su época. Tengamos en cuenta, además, que la conformación de la lógica moderna estuvo fuertemente influida por el debate de los primeros lógicos contra el psicologismo (y su programa de

\footnotetext{
${ }^{12}$ Hay que tener mucho cuidado con la interpretación de "objetivable". Hacer meramente la diferencia entre sujeto y objeto no nos salva de la posibilidad de objetivar al sujeto. Por ejemplo, si yo concibo al sujeto como entidad psíquica cuyos procesos pueden ser estudiados por una disciplina particular, digamos, la psicología, lo que tendremos, la mayoría de las veces, es que dichos procesos psíquicos son tomados como objetos de estudio. Entonces, cuando se hable de "objetivar" en lo que queda del artículo, no se entenderá esto como la interpretación forzosa de algo como un objeto físico exterior al sujeto, sino, en un sentido más general, como todo aquello que puede ser objeto de estudio, como todo aquello que puede ser un tema explícito para una disciplina particular.

${ }^{13}$ Una posible objeción es que contemporáneamente no se puede hablar de "la lógica" como si fuera un solo cuerpo unitario, sino, en todo caso, de "las lógicas", dada la variedad de ramas que se han ido abriendo, no reducibles la una a la otra, pues en algunas aceptan principios o axiomas que otras pasan por alto o rechazan. Sin embargo, incluso si tenemos en cuenta esto, lo que se quiere destacar aquí es que el carácter objetivador es algo común a todas ellas, dado que es un presupuesto que subyace incluso al establecimiento de sus axiomas, pues también estos son objetivaciones del lenguaje.
} 
fundamentar la lógica en la psicología) ${ }^{14}$. Esto tendrá importantes repercusiones, puesto que la manera en que las teorías de la verdad del siglo $X X$, dadas por autores formados en lógica, han asumido un campo de estudio que ha estado delimitado por la semántica tal como Frege la concibió. La paradoja del mentiroso, entonces, surge justamente a raíz del modo en que Frege hace tal delimitación.

En "Sobre sentido y referencia"'5 el principal escrito de Frege dedicado a la semántica y a las condiciones de predicación de verdad o falsedad, se realizan las siguientes diferencias. Si nos situamos al nivel de los objetos individuales, hay que diferenciar entre ${ }^{16}$ :

a) el signo: los nombres en tanto signos (escritos u orales)

b) la representación: lo psíquico propiamente dicho

c) el sentido (Sinn): la forma de dirigirnos a un determinado objeto

d) la referencia ${ }^{17}$ (Bedeutung): el objeto propiamente dicho.

El famoso ejemplo de Frege para esto es el de Venus. En este caso tenemos la misma referencia, un solo y el mismo objeto. Pero a él podemos dirigirnos llamándolo "el lucero matutino" o "lucero vespertino"; son dos modos distintos de aproximarnos, lo cual quiere decir que son dos sentidos distintos para una misma referencia. No obstante, también cabe diferenciar entre "the morning star" y "el lucero matutino", y lo que se tendría en este caso son dos nombres (signos) distintos para el mismo sentido. Aparte de todo esto, estarían, claro está, las representaciones, que son las vivencias individuales de cada persona que hable o escuche hablar de Venus ${ }^{18}$.

\footnotetext{
${ }^{14}$ También Edmund Husserl enfrentó esta misma amenaza del psicologismo en la primera parte de sus Investigaciones lógicas de 1900-1901. En este libro, Husserl se enfrenta tanto a los psicologistas como a los neo-kantianos en lo que respecta a la naturaleza y fundación de la lógica. La diferencia, como veremos luego, es que Husserl evita dejar de lado lo subjetivo, pero, por supuesto, lo reinterpreta para no quedar inmerso en el paradigma moderno.

${ }^{15}$ Cf. Frege, Gottlob, "Sobre sentido y referencia", en: Escritos filosóficos, Barcelona: Crítica, 1996, pp. 172-197.

${ }^{16}$ Cf. ibid. pp. 175-177.

${ }^{17}$ En algunas traducciones al castellano se vierte "Bedeutung" por "significado" o incluso por "denotación"; en otros casos, incluso se traduce "Sinn" por "significado", creando una confusión enorme entre los lectores de habla castellana. No entraremos en el debate de cuál traducción es más apropiada, sencillamente usaremos la de "referencia" por ser la de la traducción usada.

${ }^{18}$ Posteriormente, Bertrand Russell abriría, al respecto, el debate acerca de la peculiaridad de los nombres propios; es decir, el nombre "Venus" ienuncia un modo más de aproximarse al
} 
Ahora bien, lo dicho vale para los objetos individuales, el problema es que nosotros no nos relacionamos con objetos individuales aislados, sino coordinados en estados de cosas (Sachverhalten). En este sentido, el esquema señalado arriba queda modificado del siguiente modo'19:

a) el signo: las proposiciones

b) la representación: las cadenas de vivencias psíquicas

c) el sentido (Sinn): el pensamiento

d) la referencia (Bedeutung): el valor de verdad de la proposición

Sin embargo, el punto crucial es el modo en que Frege descarta, sin mayores problemas, el ámbito de las representaciones. Él las define del siguiente modo: "De la referencia y del sentido de un signo hay que distinguir la representación [Vorstellung] a él asociada. Si la referencia de un signo es un objeto sensiblemente perceptible, la representación que yo tengo de él es entonces una imagen interna formada a partir de recuerdos de impresiones sensibles que he tenido, y de actividades que he practicado, tanto internas como externas" ${ }^{20}$. Esto implica que la noción que él maneja de lo subjetivo está fuertemente marcada por el paradigma moderno de la mente como representacional; es decir, entiende a esta como generadora de imágenes de la realidad. Su noción de representación (Vorstellung) supone que el sujeto es un "compartimento" de la realidad donde hay entidades (imágenes, recuerdos, figuraciones) que se generan a partir del contacto con otras entidades externas mediante las impresiones sensibles ${ }^{21}$. Es ese particular concepto de sujeto el que Frege descarta como parte a tener en cuenta para la semántica asociada a la lógica, y la tradición que se abre con él, en gran medida, asumirá ese mismo concepto de sujeto 22 .

objeto al lado de "lucero matutino" y "lucero vespertino", o tiene algo de particular en tanto nombre propio? Para los fines de este trabajo, esa pregunta puede pasarse por alto.

${ }^{19}$ Cf. Frege, Gottlob, op. cit., pp. 178-I8I.

${ }^{20}$ lbid., p. 175 (el resaltado es nuestro).

${ }^{21}$ La manera particularmente breve de presentar lo subjetivo por parte de Frege no hace posible establecer quién o quiénes son sus autores de referencia a este respecto, pero podemos sospechar que su referente más cercano en cuanto a teoría del conocimiento es Kant. Esta sospecha se refuerza si observamos la mención a Kant en algunos de sus textos, especialmente en el que ahora nos sirve de guía, Über Sinn und Bedeutung. Sin embargo, tendría que ampliarse un estudio más detallado por este camino para poder confirmarla.

${ }^{22}$ Es obvio que hay intentos de usar elementos y teorías lógicas para analizar lo subjetivo. Las conexiones entre lógica y psicología son obviamente posibles. El punto, sin embargo, es que en estos intentos se suele asumir lo subjetivo del modo representacional, es decir, únicamente 
"La representación es subjetiva: la representación de uno no es la del otro. Por ello se dan múltiples diferencias en las representaciones asociadas al mismo sentido. Un pintor, un jinete y un zoólogo asociarán probablemente representaciones muy distintas al nombre 'Bucéfalo'. Por eso se diferencia la representación esencialmente del sentido de un signo, el cual puede ser propiedad común de muchos y que, por tanto, no es parte o modo de la mente individual" 23 . Entonces, siguiendo a Fregey dicho de manera breve, mientras que la representación es algo meramente subjetivo, el sentido es intersubjetivo, es un "tesoro común de pensamientos que transmite de una generación a otra" 24 . Esto será importante para él y los que le siguen, pues con este panorama se argumentará que el análisis de la consistencia de enunciados, por ejemplo, estará en el análisis del sentido (siempre a través de signos, pero siendo algo distinto a ellos), y el análisis de la veracidad recaerá en la referencia.

Ahora bien, es justamente este panorama o mapeo hecho por Frege el que permite que este autor descarte lo subjetivo precisamente por su carácter individual y relativo: "En lo que sigue, no hablaremos ya más de las representaciones e intuiciones; se las ha mencionado aquí únicamente para que la representación que despierta una palabra en un oyente no sea confundida con su sentido o su referencia" ${ }^{25}$. Sin embargo, nuevamente, lo que se está entendiendo por subjetivo es únicamente la representación o imagen, copia mental de la realidad que es variable de individuo a individuo.

Como sabemos, las críticas a esta concepción de sujeto en el siglo $\mathrm{XX}$ han venido desde distintas líneas; seguiremos ahora la línea seguida por la fenomenología para poder no solo reinterpretar al sujeto (tema de la tercera sección), sino también para ver cómo esto tiene consecuencias en la manera misma de entender el lenguaje, la temporalidad del habla y la referencialidad (temas de la cuarta sección).

como un conjunto de entidades psíquicas (las vivencias, recuerdos, imágenes, etc.) que sean una imagen de la realidad. Ciertamente, en gran medida lo subjetivo es eso, pero también hay una dimensión articuladora de sentido que no puede entenderse bajo el modelo representacional que Frege hereda y retransmite.

${ }^{23}$ Ibid., p. 176.

${ }^{24}$ Ibid. Nótese que en este caso "pensamiento" (Gedanke) no alude, como suele concebirse, a las representaciones, a los procesos psíquicos internos y personales. Para Frege, "pensamiento" alude al ámbito intersubjetivo del sentido.

25 Ibid., p. 177. 


\section{§ 3. La reinterpretación del sujeto por parte de la fenomenología}

¿Cómo podemos reinterpretar, entonces, al sujeto? Lo que queremos mostrar ahora es el modo en que la fenomenología reinterpreta la noción de sujeto. Para hacerlo, nos concentraremos brevemente en lo que Husserl y Heidegger pueden decir al respecto. Veremos entonces cómo, en las Investigaciones lógicas ${ }^{26}$, Husserl efectúa dicha reinterpretación y, posteriormente, cómo, en Ser y tiempo ${ }^{27}$, Heidegger pone todo el énfasis en la condición no-objetivable, no-entificable del ser humano. La exposición no entrará en detalles pues lo que nos interesa en este momento es mostrar qué otras posibilidades tenemos para interpretar al sujeto y al lenguaje.

El caso de Husserl es altamente rescatable para este contexto, dado que puede decirse que establece una diferencia muy parecida a la que efectuaba Frege, puesto que para él también cabe diferenciar entre ${ }^{28}$ :

a) el signo (significativo) ${ }^{29}$

b) la representación: la vivencia psíquica, subjetiva, personal

c) la significación (Bedeutung) ${ }^{30}$ : la manera en que mentamos un determinado objeto

d) la objetividad propiamente dicha

Lo importante es que Husserl, a diferencia de Frege, no descarta el ámbito psíquico, sino que, rescatando (y reinventando) la noción de intencionalidad, logra darle a la vivencia un papel central para la lógica, y no solo para esta, sino

\footnotetext{
${ }^{26}$ Cf. Husserl, Edmund, Investigaciones lógicas, Madrid: Revista de Occidente, 1976.

${ }^{27}$ Cf. Heidegger, Martin, Ser y tiempo, Santiago de Chile: Editorial Universitaria, 1997.

${ }^{28}$ Cf. especialmente el $\S 48$ de los "Prolegómenos a la lógica pura" (primer volumen de las Investigaciones lógicas) y el primer capítulo de la "Primera investigación lógica", especialmente los $\S \S 7-12$.

${ }^{29}$ Husserl diferencia el signo significativo del signo indicativo, la diferencia entre ambos es la diferencia entre el signo en tanto instancia del lenguaje humano (las letras de un texto, por ejemplo) y el signo como señal (como cuando decimos que la huella es signo del pie).

${ }^{30}$ Husserl coloca, en las Investigaciones lógicas, a "Bedeutung" como sinónimo de "Sinn". Cabría anotar marginalmente que posteriormente, en Ideas I (§ I24), una vez abierto el análisis trascendental, Husserl diferenciará ambos términos. "Sinn" pasa a indicar el componente de sentido a nivel perceptivo, mientras que "Bedeutung" pasa a indicar el componente de sentido a nivel lingüístico.
} 
para cualquier actividad humana ${ }^{31}$. En las Investigaciones lógicas, el análisis de la subjetividad tiene su tratamiento más detallado en la Quinta Investigación, y lo primero que hace ahíi ${ }^{32}$ es distinguir tres nociones de conciencia para mostrar desde el inicio cuál será su propuesta. Estos tres sentidos distintos de conciencia son:

I. como total consistencia fenomenológica del yo empírico, como entrelazamiento de vivencias psíquicas,

2. como percepción interna de las vivencias psíquicas,

3. como toda clase de "actos psíquicos" o "vivencias intencionales".

El primero es un sentido psicológico-descriptivo. Aquí se habla de las vivencias como contenidos de conciencia ${ }^{33}$. Se referiría a la psique como un conjunto de vivencias que corresponderían a las objetividades externas y a sus propiedades (por ejemplo, a un color le corresponde una sensación de color). En este sentido, se toma a la conciencia como un ámbito de lo real junto a otros, un ámbito de procesos reales ${ }^{34}$.

El segundo es el concepto de conciencia interna. Se trata de la "percepción interna" mediante la cual uno es capaz de, por así decirlo, "ver dentro de sí" para fijarse únicamente en los procesos psíquicos, dejando de lado su correlato objetivo exterior. Sin embargo, Husserl termina señalando que este concepto corresponde más al de vivencia que al de conciencia.

El tercero es el de conciencia como acto o vivencia intencional. Es recién aquí donde se menciona la importancia del rescate brentaniano de la intencionalidad. Husserl hereda este término resignificándolo para enfatizar que, de modo a priori, nosotros estamos ya siempre dirigidos hacia una objetividad determinada,

\footnotetext{
${ }^{31}$ Esto lo hace a tal punto que podríamos decir que la finalidad de las Investigaciones lógicas consiste en explicar en qué consiste el conocimiento. Este sería el resultado de la coincidencia de dos tipos distintos de vivencias: la vivencia significativa, es decir, aquella por la cual hacemos mención a algo (esté o no presente), y la vivencia intuitiva, por medio de la cual una objetividad (real o ideal) se me hace presente. Lo que queda resaltado de esto es que en todo momento Husserl ha seguido el hilo de la conciencia en cuanto conciencia intencional para explicar su propuesta.

${ }^{32}$ Cf. Husserl, Edmund, Investigaciones lógicas, p. 475.

${ }^{33}$ Cf. ibid. p. 476.

${ }^{34}$ En la terminología posterior de Husserl, podríamos decir que se trata de una región del ser de lo psíquico.
} 
y esta direccionalidad subyace a las separaciones entre representaciones, juicios, etc. ${ }^{35}$ La intencionalidad, es decir, la posibilidad de la psique humana para "dirigirse a", es lo que permite resignificar lo que pueda entenderse por conciencia o sujeto como conciencia intencional o sujeto intencional. Lo subjetivo, entonces, no sería únicamente un ámbito de la realidad, es también la capacidad misma de dirigirnos hacia cualquier tipo de objetividad, sea esta del sentido externo o interno. En otras palabras, por ejemplo, tanto si me dirijo a un auto, como si estoy pensando en un dolor de muelas, como si me vuelco sobre antiguos recuerdos, en todos estos casos soy yo el que se dirige, el que piensa, el que se vuelca. Hay así una diferencia a marcar entre lo juzgado y el juzgar, entre lo pensado y el pensar, entre lo percibido y el percibir, entre algo amado y el $\mathrm{amar}^{36}$. De esta manera, no puede decirse que la psique simplemente cree imágenes cual espejo, teniendo a la realidad exterior como modelo; la psique, además de sus elementos sensibles, tiene una dimensión intencional y como tal está siempre operante en todo acto de lógica, matemática, ciencia o la actividad que fuese. $Y$ es que, siendo intencional, la conciencia ya no puede interpretarse simplemente al modo de una objetividad, puesto que es acto.

Heidegger ${ }^{37}$ sigue esta misma línea, pero de forma tal que enfatizará aun más el carácter no objetual del ser humano. Él señala, en Ser y tiempo, que la estructura propia de este ente, al que se referirá como Dasein ${ }^{38}$, viene constituida por lo que él llama estar-en-el-mundo (In-der-Welt-sein). En su propuesta, el mundo no puede entenderse como algo que esté simplemente delante de nosotros, como algo diferente y enfrentado al Dasein, sino que es algo en lo cual nosotros ya estamos inmersos, algo en lo cual nos desenvolvemos ocupándonos con las cosas. Pero esta ocupación no se realiza de un

\footnotetext{
${ }^{35}$ Cf. ibid., p. 492.

${ }^{36}$ Para una explicación más detallada, cf. ibid., pp. 490-492. Lo que nos interesa rescatar en este momento es que la diferencia entre lo percibido y el percibir no es asimilable a la diferencia propia del paradigma moderno entre lo percibido y la imagen psíquica que se construiría al estar en contacto con lo percibido. Por así decirlo, el percibir (en cuanto intencional), desbarata el hiato que la mayoría de autores modernos coloca entre "el afuera" y "el adentro".

${ }^{37}$ Advierto que trataré de hacer a este autor lo más comprensible que pueda. Por esto no usaré muchas citas sino que trataré de usar ejemplos en varios pasajes. Esto, obviamente, le disminuye a la exposición rigurosidad, pero permite ganar claridad para quienes no tengan ningún conocimiento de Heidegger.

${ }^{38}$ Esta no es simplemente una nueva terminología. Se trata del intento de vincular al ente que somos nosotros con el tema de su proyecto: la pregunta por el sentido del ser.
} 
modo tal que uno tematice y analice dichas cosas, como en la actitud, por ejemplo, del hombre que hace ciencia (o, para nuestro caso, que hace lógica). Este "estar inmerso en las cosas" 39 es importante, pero no porque anule aquel otro modo de estar en el mundo por medio del cual tomamos a las cosas como objetividades a las que se puede analizar, tematizar, escudriñar; nada más lejos de la propuesta de Heidegger. Se trata más bien de mostrar cómo ese "estar inmerso" es un modo más originario de estar en el mundo que el modo de ser implicado en la tematización.

Ahora bien, ipor qué se trataría de un modo "más originario"?, ipor qué no se los puede declarar únicamente un modo junto a otro sin que sea necesario compararlos? Veámoslo con un ejemplo: si yo me encuentro escribiendo una carta a un amigo, estoy completamente abocado a las palabras que escribo, en aquello que quiero transmitirle, pero al hacer esto el lapicero con el que escribo no es siquiera algo de lo que me percate, se podría decir que es como una extensión de mi mano, de mi cuerpo; estoy inmerso en el uso del lapicero, no estoy abocado hacia él, sino hacia lo que con él escribo. Si por una torpeza dejo caer el lapicero al suelo, entonces sí estaría abocado a él, pero al hacerlo tengamos en cuenta que, por ejemplo, mi mano que va a recogerlo sigue como algo de lo cual no me percato. Y si continúo, ¿dónde termina esta remisión?, ¿en la mente, en el cerebro, en una teoría de la creencia y de la intención? En ninguna, puesto que en el momento mismo en el que empiezo a abocarme a ello, inmediatamente habrá un trasfondo para aquello a lo que me aboco. Pero este trasfondo no es una entidad, ni en el caso de arriba, puesto que al momento de escribir la carta, el lapicero no era una entidad; más bien cobra recién el carácter de entidad desde el momento en que me agachaba a recogerlo. A esto se podría replicar tal vez algo como "¿Cómo que no es una entidad?; el que no me concentre en ella no quiere decir que deje de ser un objeto". De ahí que debamos tener mucho cuidado. Quien lo concibe de esta manera no ha comprendido la sutileza que el análisis de Heidegger pide. No se trata de una entidad (carta), junto a otra (lapicero), junto a otra (mano),

\footnotetext{
${ }^{39}$ Heidegger usa el concepto de "sein bei den Dinge", que podríamos traducir al castellano con el arcaísmo "estar do las cosas", pues el "bei" no tiene el sentido de un "en" (que hace pensar mucho en posicionamiento espacial) o de un "con" (que indica contigüidad). Sería cercano al sentido del "donde" usado en frases como "voy donde el doctor". Remite, pues, a un estar inmerso en la situación.
} 
pues quien así se exprese está colocando a los tres como objetividades. Por así decirlo, quien hace esa crítica se imagina a sí mismo viendo a la vez las tres cosas, se está abocando a las tres cosas. No está respetando el que se trate de algo secuencial: quiere captar toda la situación de un solo golpe. Sería cuestión de decirle a esta persona: "Está bien, pero ahora date cuenta de que al mirar las tres cosas como estando ahí delante de ti, habría que decir que no estás pensando en tu globo ocular". Pero algo muy serio también ha ocurrido en la desatención por parte de este posible crítico: el tiempo ha quedado anulado. Él ha interpretado el ejemplo puesto líneas arriba como si se pudiera asir todo "de un golpe".

Retomando el hilo anterior, yo puedo seguir remontándome del lapicero a la mano, y de esta al brazo, o al ojo, etc., pero, como ya vimos, parece ser que cada vez que yo me desplazo de uno a otro, el primero se "hunde" en el trasfondo ${ }^{40}$, dejando de ser, propiamente hablando, una entidad ${ }^{41}$. Mientras yo escribía la carta, esta era una entidad; pero, en cuanto me fijo en el lapicero, el lapicero viene a ser una entidad, mientras que la carta deja de serlo. Pero dejar de serlo no implica en lo más mínimo que, una vez recogido el lapicero, yo vuelva a la carta y esta vuelva a ser una entidad ( $y$ el lapicero deje de serlo). ¿Qué implica eso?, ¿en dónde "se hunde"? La respuesta que da Heidegger es que ese "dónde" se hunde no es una entidad más. Se trata de la apertura misma ${ }^{42}$ del ser humano hacia el mundo ${ }^{43}$, apertura que no es un ente, pero, puede decirse, es condición para la aparición de cualquier ente. Es algo siempre presupuesto y, a la vez, imposible de entificar. Sin embargo, esa apertura puede ser descrita "retrospectivamente", por así decirlo, y podemos darnos cuenta de que ahí yace nuestra capacidad de articulación de sentido. A esta capacidad (que es uno de los existenciales de la constitución

\footnotetext{
${ }^{40}$ Husserl diría que cada vez que yo me dirijo a un determinado objeto, los demás objetos que lo rodean quedan en el horizonte inactual de intuición o significación.

${ }^{41}$ Estoy usando "entidad" como sinónimo de "ente". Advierto que hago esto solo con fines de explicación y porque no necesito, para el tema de este artículo, entrar en el detalle terminológico en que entra Heidegger. En Heidegger sí se diferencian (diferencia entre Wesenheit y Seiende).

${ }^{42}$ En el fondo, todo el desarrollo de la primera sección de la "Primera parte" de Ser y tiempo apunta a realizar este análisis. El plan del proceso se halla especialmente en el $\S 12$.

${ }^{43}$ Téngase esto en cuenta cuando Heidegger hable de esta apertura como el $\mathrm{Da}$ (ahí) que se analiza con el "estar-en" (In-sein), constituido por lo que él llama "existenciales".
} 
de la apertura, junto con la disposición afectiva y el comprender ${ }^{44}$ ) es a la que Heidegger llamará discurso o habla (Rede), cuya manifestación en el mundo es el lenguaje (Sprache) $)^{45}$. $Y$ es del lenguaje del que depende que nosotros podamos entificar una entidad.

Para entender un poco más el tema del lenguaje, pensémoslo de este modo. Volvamos al ejemplo y preguntemos: una vez que nos abocamos al globo ocular, ¿qué queda como telón de fondo no captado?, iel nervio óptico? Y luego iel cerebro?, ¿y si me aboco ahora al cerebro?, etc. En otras palabras, ihasta dónde se podría llegar con esta remisión? Los ejemplos de "nervio óptico" y "cerebro" son asequibles al sentido común. Pero si no tuviésemos conocimiento de ellos, si no formaran parte de nuestro vocabulario, probablemente habría que seguir esa cadena pasando del ojo al alma o algo similar. ¿De qué depende esto entonces? Del lenguaje, claro está ${ }^{46}$. Si recordamos lo explicado anteriormente sobre cómo es que algo llega a ser una entidad en el desplazamiento de nuestra abocación, entonces se podría decir que el que la entidad se me presente depende del lenguaje, de los sentidos conferidos. Entonces, es el lenguaje el que nos permite entificar la carta o el lapicero. Consideremos el siguiente ejemplo: al fijarnos en la carta, además del lapicero teníamos en el trasfondo de lo que me rodeaba también un aparatito no reconocido. Al mirar el panorama sin saber de qué se trata, probablemente ni lo identificaríamos. Pero si alguien posteriormente nos explica que se trata de un USB y cuál es su uso determinado, empezaremos, entonces, a reconocerlo como tal. Antes de la explicación no tenía la posibilidad de hacérseme manifiesto qua USB, sino a lo sumo como un "aparato". Con la explicación, hemos logrado re-estructurar nuestra trama de sentidos de forma tal que ahora sí es posible tener al USB como una entidad en caso de que sea llamado a presencia en el hablar.

Lo que nos falta, una vez que se ha aclarado todo esto, sería preguntarnos lo siguiente: ¿qué sucede con la proposición? Ella respondería a lo que varias líneas arriba llamábamos el modo de estar en el mundo que tematiza, objetiviza, escrutiña a alguna objetividad. En nuestro ejemplo, la persona que redactaba la carta no llegó nunca a este modo de estar, que es más propio de

\footnotetext{
${ }^{44}$ Cf. Heidegger, Martin, op. cit., §§ 29-33.

${ }^{45}$ Cf. ibid., p. II4.

${ }^{46}$ Sobre el leguaje, el habla y el sentido, véase ibid., § 34.
} 
la actitud científica. Veámoslo con una variante del ejemplo: imaginemos que Frege le escribe una carta a Russell en la que primero lo saluda, le pregunta por su familia y, segundo, pasa a temas relativos al análisis proposicional de lógica, escribiendo funciones, proposiciones, etc. Habría una diferencia importantísima a notar entre las dos partes; cualquier persona que haya leído un libro de lógica o matemática debe haber sentido ese leve cambio que hay entre leer la explicación del autor de, por ejemplo, lo que es una proposición, y leer las partes en que hace una derivación por ejemplo. llustremos esto: cuando Frege escribía y luego Russell leía la carta, en la parte amical ambos estaban, por así decirlo, inmersos o perdidos en las palabras, se dejaban llevar por ellas; pero, cuando pasaban al análisis de las proposiciones, debían tratar a estas como objetos que estén ahí delante para ser analizados. No es simplemente que estén abocados a las proposiciones, hay algo más. Este otro abocamiento (menos originario, como decíamos antes) nos aleja de y nos coloca ante el objeto. Si se quiere hacer un paralelo con el primer ejemplo, la diferencia entre los dos tipos de "abocarse a" estaría en la diferencia entre abocarme a recoger el lapicero (lo miro, pero no con intención de escudriño) y aquel otro que tendríamos que dedicarle si este deja de escribir pero constatamos que tiene tinta. Cuando pasa esto, nos preguntamos si no será por alguna pequeña burbuja de aire en la tinta o porque la temperatura es tan baja que la tinta no fluye, etc. En todo caso, es una tematización explícita y objetivadora del lapicero.

Esto puede ampliarse a todo nuestro trato con objetividades para mostrar cómo este último modo de estar en el mundo es menos originario: no solo porque se puede decir que no siempre se da, mientras que el otro tipo de abocarse sí, sino porque también está presupuesto. Es decir, cuando reviso la tinta del lapicero, no deja de ser cierto que mis manos siguen siendo únicamente trasfondo. En el caso del lenguaje, esto vale para las proposiciones, que no serían sino algo fundado en el habla (Rede). Son una forma del lenguaje, es cierto, pero una forma no entificable, no objetivable, $y$ esto es lo que nos interesa rescatar para el análisis de lo implicado en la paradoja.

Para concluir con esta sección, solo tendríamos que señalar que los planteamientos de Husserl y Heidegger son obviamente muchísimo más complejos de lo que la actual presentación nos permite mostrar. Sin embargo, basta con 
lo dicho para reconsiderar lo que puede entenderse por "subjetivo" o "conciencia”, así como lo que dicha reconsideración acarrea para el lenguaje. Para hacer más llevadera la argumentación que continúa y no tener que volver a la terminología particular de cada autor, usaremos el siguiente vocabulario: para aquella manifestación del lenguaje como algo a lo que nos enfrentamos, como un ente intramundano, diremos que se trata del lenguaje en tanto lo dicho; mientras que para la capacidad articuladora de sentido, que es una actividad del ser humano en tanto ser lingüístico, diremos que se trata de su decir ${ }^{47}$.

\section{§ 4. Repercusiones de la reinterpretación del sujeto en la problemática de la paradoja del mentiroso}

Habiendo revisado la concepción del sujeto de Frege (y, de ahí, la de la lógica del siglo $X X)$, que consiste en entenderlo como un conjunto de elementos sensibles (las vivencias), y habiendo visto cómo podemos reconsiderar al ser humano como un ente que articula y da sentido, ya podemos sacar consecuencias para el problema de la paradoja del mentiroso.

\footnotetext{
${ }^{47}$ Puede ser que la tradición de autores en lógica y en la semántica a ella asociada no se sientan, pues, cómodos al moverse en un terreno en el que se incluye algo que no puede ser convertido en una objetividad, en un ente determinado, pero que a la vez está supuesto por cualquier ente. Justamente en esto radica la propuesta de solución, en no quedarse únicamente con el lenguaje como objetivable. Uno pediría, sin embargo, fijarse en un par de autores que van más allá de la dimensión entitativa del lenguaje. En primer lugar, habría que considerar a Kant, que tiene una repercusión en la tradición de lógicos y analíticos directa o indirectamente. Cuando Kant habla de las condiciones a priori de posibilidad del conocimiento (es decir, las formas puras de la intuición, espacio y tiempo, y las categorías) no habla de ellas como entidades, sino más bien como lo presupuesto por las entidades. En segundo lugar, tenemos una voz más contemporánea: J.L. Austin (Palabras y acciones: cómo hacer cosas con palabras, Buenos Aires: s/e, 197I). Al hablar del uso performativo del lenguaje (por ejemplo, cuando un sacerdote dice "Yo los declaro marido y mujer"), es bastante claro en señalar que no se trata de una proposición. $\mathrm{Si}$ bien es obviamente posible obtener una proposición (por ejemplo: "El sacerdote los declaró marido y mujer"), justamente en el momento de transformarla ya ha perdido su carácter de acto de habla (speech act), su carácter performativo. Algo que podemos rescatar de Austin es que logra sugerir que en todo uso del lenguaje, incluso cuando el lógico opera con proposiciones, hay siempre también una cierta dimensión performativa.
} 


\section{§ 4.I. Aplicación de la reinterpretación del lenguaje para la lógica: cuestionamiento de los niveles del lenguaje}

Lo primero en lo que tendríamos que reparar es en que, si tomamos en cuenta aquel ámbito articulador de sentido que no es él mismo una objetividad, sino que es posibilidad de tales objetividades, tendríamos que decir, entonces, que el fenómeno lingüístico no se reduce a las proposiciones. Tengamos esto en claro: las proposiciones, tal como las entiende la lógica, son objetividades; son, por así decirlo, objetos lingüísticos ${ }^{48}$ a los que nosotros podemos dirigirnos como a cualquier otro objeto; podemos tenerlos frente a nosotros de forma tal que sean susceptibles de ser inspeccionados. Es este el ámbito del lenguaje que puede ser tematizado como algo, como una entidad en el mundo susceptible de análisis. De esta manera, así como la botánica analiza determinado tipo de objetividades; la química, otro tipo; las ciencias sociales, otro tipo; también la lógica objetiviza su tema de estudio y hace de él un objeto lingüístico formalizado (proposiciones, funciones, etc.) ${ }^{49}$. Esto es importante porque el problema con las soluciones de Russell, Tarski y Kripke, entre otras, es que al construir niveles de lenguaje no están lidiando con el lenguaje más que en su dimensión objetual, la dimensión de lo dicho, olvidando con ello la dimensión del decir mismo. En jerga heideggeriana, el problema es que sus posturas implican una continua conversión del habla en ente, de forma tal que se olvida lo que el habla propiamente es. Podemos verlo del siguiente modo: en cada nuevo subir de nivel, el nivel inferior queda entificado. Pero ya hemos visto que a esto no se reduce el lenguaje.

¿Qué consecuencias se pueden sacar de esto? Lo analizado anteriormente nos encamina a una consideración sobre el metalenguaje. La forma típica de entender al metalenguaje es como la de una proposición que se refiere a otra que está en el lenguaje objeto, generando así dos “capas” o “niveles" de lenguaje, $y$ esto es iterable generando, para los lenguajes naturales ( $y$ en gran

\footnotetext{
${ }^{48}$ De ahí también, por lo tanto, que la concepción de la verdad como correspondencia suponga que esta se tienda entre un enunciado, es decir, un objeto lingüístico, y un objeto o situación. Es decir, la teoría de la verdad como correspondencia no es, en el fondo, sino la teoría que indaga por las condiciones para la concordancia de dos objetos.

${ }^{49}$ Esto no es algo exclusivo de la lógica ( $y$, para el caso que aquí revisamos, de su concepción de la semántica); también la lingüística, al menos en sus ramas más formales, pasa por concebir al lenguaje de este modo.
} 
medida también para los artificiales), potenciales niveles infinitos. Ahora bien, cuando una persona dice o lee un enunciado en el que haya más de un nivel de lenguaje, no sucede que en todo momento se tenga presente la multiplicidad de niveles, sino que siempre nos referimos solo a uno de ellos, aunque, claro está, uno puede "desplazarse" de uno a otro según lo requiera el enunciado. Un ejemplo del lenguaje natural puede servir de ilustración. Supongamos que en un salón de clase, un niño, Julio, le dice a otro: "Lo que dijo María, es decir, 'Esperanza dijo: 'El primer ejercicio daba como resultado que era falso' y eso es verdad', es falso". Se tendrían aquí tres niveles de proposiciones:

$$
\begin{aligned}
& F=\text { lo que dijo María, es decir, } G, \text { es falso }\left(L_{2}\right) \\
& G=\text { Esperanza dijo } H, \text { y eso es verdad }\left(L_{1}\right) \\
& H=\text { el primer ejercicio daba como resultado que era falso }\left(L_{0}\right)
\end{aligned}
$$

La primera pregunta que debe hacerse es: ¿dónde queda Julio en este esquema? Julio es quien dice, no es parte de lo dicho. Claro está que alguien, por ejemplo Abigail, puede intentar construir $L_{3}$ y generar:

$E=$ Julio enunció $F\left(L_{3}\right)$

Esta es una posibilidad, claro está, pero una posibilidad que pasa, nuevamente, por convertir el decir en algo dicho, en una objetividad. Se podría repetir la pregunta al siguiente nivel: iy dónde está Abigail?, etc. Esta es justamente la limitación de la lógica que intentamos sacar a la luz.

Una vez que se tiene esto en claro, cabría entonces preguntarse cómo funciona, en cuanto acto, la lectura de aquella proposición enunciada por Julio. Pedimos al lector que haga una suerte de ejercicio y se percate de lo siguiente: resitúese en el momento en que estaba leyendo las líneas escritas más arriba, justo antes de la proposición enunciada por Julio; mientras lo hacía estaba, por así decirlo, inmerso en mis palabras, y se colocaba en lo que podríamos llamar el "lugar de enunciación" 50 que yo mismo tenía al redactar estas líneas;

\footnotetext{
${ }^{50} \mathrm{El}$ uso de esta frase puede traer problemas especialmente a quienes estén acostumbrados a usar giros como "lugar de enunciación" para hablar de otros temas de filosofía como la dinámica de la comprensión entre los hablantes o las explicaciones del fenómeno de la empatía. En este caso, no estamos yendo a un nivel tan detallado, no queremos dar a entender, por ejemplo, que uno esté intentando comprender las motivaciones o razones de Julio o que uno tenga una relación empática con un personaje ficticio. Lo único que se está queriendo mostrar es que uno tiene la capacidad de diferenciar, aunque se encuentren en un mismo texto, los discursos
} 
luego se dijo que se mostraría qué es lo que dijo Julio y, a partir de ese momento, uno adopta el lugar de enunciación de Julio y así uno lee lo que este personaje ${ }^{51}$ dijo $\left(L_{2}\right)$; posteriormente vuelve a hacerse dicho desplazamiento para tomar el lugar de enunciación de María y finalmente el de Esperanza. Lo central aquí es notar que el lector recorre los distintos "niveles", pero se enfrenta a ellos uno por uno, desplazándose de uno a otro. En este sentido, uno no se enfrenta a todos los niveles de un discurso a la vez, como quien ve un edificio de varios pisos o un gráfico estadístico de varias barras. Uno solo tiene en frente un nivel de texto: en el momento de la lectura efectiva de un lenguaje natural, uno sólo puede aprehender temporalmente un discurso a la vez. Para el ejemplo: “Lo que dijo María, es decir” (desplazamiento), “Esperanza dijo" (desplazamiento) "El primer ejercicio daba como resultado que era falso" (desplazamiento) "y eso es verdad" (desplazamiento), "es falso". Claro está que uno usualmente sabe cómo resituarse en un lugar de enunciación anterior y darse cuenta, por ejemplo, de que "Lo que dijo María, es decir" y "es falso" se enuncian desde el mismo lugar (incluso si nos toma un tiempo saber ubicarnos adecuadamente).

Todo este ejercicio tuvo como objetivo ilustrar una idea básica: uno siempre se enfrenta únicamente a un solo nivel del lenguaje en la lectura de lenguajes naturales y se hace desde nuestra capacidad de dar sentido a los signos. El punto es que, mientras que estamos enfrentados a un lenguaje natural y lo

de varios personajes. Por ejemplo, al leer una obra teatral uno de facto distingue entre lo dicho por cada uno de los personajes; cada vez que uno de ellos deja de hablar e interviene otro, el lector realiza un "desplazamiento de lugar de enunciación" y asume que son líneas que pertenecen a distintos personajes. El punto a resaltar aquí es que la asignación de un discurso a un personaje no es del tipo de la asignación de un elemento a un conjunto: quien lee el texto sigue el discurso, pero va asumiendo la perspectiva de enunciación de cada personaje. De ahí que, por ejemplo, si se llega un punto en que se ha perdido y ya no sabe qué línea asignar a cada personaje, uno desconfía de las asignaciones de las líneas anteriores también y regresa las páginas hasta buscar el punto en que estaba seguro. Lo central es que, cuando esto pasa, uno puede empezar a ponerle marcas a cada línea para no extraviarse de nuevo (tomando distancia con respecto al texto), en este momento sí puede decirse que se trata a las líneas y los personajes como elementos y conjuntos; empero, luego, al releer para comprender, uno volverá a estar inmerso en lo que las palabras dicen y esto implicará que la asignación de cada línea a cada personaje se realice mediante aquel desplazamiento de lugar de enunciación que se efectúa al seguir el diálogo, proceso que no implica únicamente lo dicho por cada personaje, sino también el decir de cada uno de ellos.

${ }^{51}$ Para estos fines, no hay necesidad de entrar en el problema de diferenciar un enunciante real de uno ficticio, pues lo que nos interesa es que a alguien se le adjudique un discurso y aparezca en el contexto del diálogo como un personaje capaz de articular sentido. 
leemos efectivamente, estamos inmersos en el sentido cargado en los signos. En este momento, la capacidad de dación de sentido está funcionando en la lectura efectiva del texto.

Para que se genere la paradoja, entonces, uno tiene que hacer la siguiente operación: debe poder tomar distancia con respecto al texto de tal forma que se lo pueda ver como un objeto de análisis; en ese momento de la toma de distancia, el lenguaje empieza a ser entendido como un conjunto articulado de enunciados. La paradoja depende de que uno interprete "esta oración es falsa" como un enunciado, como un objeto lingüístico. Vale decir, cuando uno toma tal distancia con respecto a lo leído, uno deja de estar inmerso en los signos y coloca al discurso como algo a analizar, como un objeto. Esto se efectúa cada vez que en un escrito se entrecomilla algo o se lo escribe en un renglón aparte ${ }^{52}$.

Esta operación de toma de distancia y su consiguiente objetivación del lenguaje está ya presupuesta cuando, en lógica, un texto determinado es convertido en variables. La formalización del lenguaje, en la que los enunciados sean escritos como variables ( $\mathrm{F}, \mathrm{G}$, etc.), es un paso extra para conseguir un objeto lingüístico más simple y claro; sin embargo, el lenguaje ya estaba concebido como objeto con anterioridad. Es mediante ese paso que se puede pretender hablar de niveles del lenguaje y por tanto de un metalenguaje. No hay motivo para rechazar que se haga tal operación con el lenguaje, siempre y cuando se tenga en cuenta que hay una capacidad de articular sentido (por esencia no entificable) que está siempre operando en todo momento. Los problemas surgen cuando esto último se olvida y, según la terminología que se ha venido usando, se asimila todo el lenguaje a lo dicho, dejando así en el olvido al decir.

Lo que también se ha dejado ver con lo anterior es que hay un flujo temporal del decir que la lógica, en su constante intento por convertirlo en algo dicho, no puede reconocer. Si uno se queda únicamente con lo dicho, con el lenguaje objetivado, entonces se pierde de vista la temporalidad propia de la vivencia, una temporalidad que no es aquella que se calcula con instrumentos de medición (más rústicos o más precisos). Esta última es una temporalidad que

${ }^{52}$ Frege ya advertía esto cuando señalaba que cuando una palabra está entrecomillada, su nueva referencia es su sentido habitual y no ya su referencia habitual. Cf. Frege, Gottlob, op. cit., p. 175. 
concibe al tiempo como secuencia de intervalos, como "la distancia entre dos puntos de tiempo", y que está marcada, entonces, por una concepción del tiempo a partir de los objetos ${ }^{53}$.

\section{§ 4.2. Revisión de la paradoja}

Una vez que se tiene en claro cómo el sujeto, el lenguaje y la temporalidad pueden ser entendidas de un modo distinto a aquel que presentan las disciplinas objetivas, entonces estamos en condiciones de entender por qué enunciábamos en un inicio que el núcleo del problema de la paradoja se debía a sus limitaciones de nacimiento y que el modo de resolverla se encontraba en darse cuenta de que las proposiciones, realmente, no tienen la capacidad de referencia que se les suele asignar.

Observemos qué pasa realmente al pronunciar "Esta oración es falsa”. Hágalo el lector en este momento (solo efectuándolo puede llegar uno a notar la sutil pero importante diferencia temporal y de lenguaje implicada). Al momento de hacerlo repare, siguiendo lo que ya hemos expuesto, en cómo hay una diferencia entre decir la oración (la creación y articulación del sentido) y la misma como algo ya dicho ( $y$, en tanto tal, como susceptible de interpretarse desde la lógica como un enunciado). Pensémoslo así: si en "Esta oración es falsa" el "esta" aludiera a otro enunciado como "La nieve es verde" no habría ningún problema. Lo que pediríamos ahora es que, al juzgar "La nieve es verde" en tanto enunciado, no se tome a "Esta oración es falsa" como otro enunciado, como algo ya dicho, sino que se ejecute su enunciación. En otras

\footnotetext{
${ }^{53}$ Este llamado de atención es hecho por primera vez por Husserl en sus Lecciones de fenomenología de la conciencia interna del tiempo, texto basado en unas lecciones de 1904-1905 en las que diferencia el flujo temporal de la conciencia del tiempo tal como lo entienden las ciencias, asignando, así, mayor profundidad a la primera. Hay que evitar, al interpretar a Husserl, creer que esa temporalidad de la conciencia se refiere a que el conteo que uno realiza in mens funda aquel otro que uno realizaría con ayuda de un reloj. No se está refiriendo a que uno pueda generar una especie de "reloj interno" que sería más confiable que los "relojes externos" (hacer esto sería caer en una suerte de inmanentismo). A lo que se refiere Husserl es al flujo de la conciencia en tanto intencional, en tanto "dirigirnos hacia". Esta es la temporalidad que estaría a la base del tiempo como duración de un intervalo, pues estos intervalos son más bien propios de aquello "hacia lo que nos dirigimos" no el del "dirigirme hacia". Heidegger, por su lado, rescata esa noción husserliana para su propia concepción del tiempo. Cabe anotar que hay múltiples puntos en los que Heidegger critica a Husserl, especialmente con respecto a su etapa trascendental, sin embargo, estos temas sobrepasan los límites de este escrito.
} 
palabras, se pide que se mantenga a "Esta oración es falsa" como decir, que no se la asimile a lo dicho. Se debe notar entonces que la deixis del "esta" solo tiene lugar cuando alguien la efectúa (mediante el pronunciamiento o mediante la lectura), pero lo principal a notar es que en este caso, para que se forme la paradoja, esa efectuación, ese decir, tiene que tratarse a sí mismo como algo dicho. Tomando esto en cuenta, la autorreferencialidad del enunciado se disuelve. Pero no solo ella, sino también el que la referencialidad en general sea asignada como algo de los enunciados ${ }^{54}$.

Replanteado de este modo, el panorama que se nos ofrece ahora y su reinterpretación de lo implicado en la referencialidad nos permite también sortear los retos propios de la paradoja reforzada del mentiroso y de la mutua referencialidad. En el primer caso, porque el reforzamiento entra en juego únicamente si todo lo que está en juego son proposiciones, y ya vimos que de lo que se trata es de mostrar que el lenguaje no se reduce únicamente a ellas. En el segundo caso, porque tal como la versión simple de la paradoja depende de que no se tenga en cuenta la temporalidad, también la versión reforzada depende de lo mismo al hacer que la mutua referencia se entienda como una remisión que opera simultáneamente de ida y vuelta de lo dicho por un hablante a lo dicho por el otro, sin tener en cuenta el acto enunciativo (el decir). El tiempo debe poder concebirse como reversible para poder hacer la ida de un enunciado $A$ hacia uno $B$ y luego la vuelta al enunciado $A$. Pero concebir de esta manera al tiempo es concebirlo justamente teniendo en cuenta al tiempo como intervalos, como la temporalidad propia de lo dicho, olvidando aquella otra del decir.

Finalmente, solo me quedaría acotar que la intención de este escrito no ha sido en modo alguno señalar a la lógica como una disciplina que deba ser dejada de lado por tener compromisos que ya han sido cuestionados por otros pensadores, sino solo mostrar que dichos compromisos limitan su alcance. La intención era justamente mostrar que dichos límites no suelen ser tenidos en cuenta claramente. La paradoja del mentiroso no es sino la expresión más resaltante de esto.

\footnotetext{
${ }^{54}$ Otro tema obviamente asociado a todo esto es el de la verdad. En el § 44 de Ser y tiempo, Heidegger, siguiendo con la línea establecida más arriba, reinterpretará este concepto para mostrar una concepción más originaria que aquella de la correspondencia.
} 
